\title{
Internacionalização na educação superior e mobilidade estudantil: 0 vai e vem de jovens acadêmicos
}

\author{
Internationalization in higher education and student mobility: \\ the going and coming of students
}

\author{
Elisabete Monteiro de Aguiar Pereira* \\ Márcia Regina Selpa Heinzle \\ Marialva Moog Pinto ${ }^{* * *}$
}

\section{Resumo}

O texto apresenta relato de uma pesquisa que teve como foco investigar a internacionalização promovida pelos programas de mobilidade estudantil. Considerando a internacionalização um dos aspectos em que a universidade brasileira teve um bom protagonismo nos últimos anos, o texto analisa experiências de estudantes brasileiros que estudaram em outros países e de estudantes africanos que estudaram em Instituições de Educação Superior no sul do Brasil. Serão apresentados apenas dois focos entre os vários pesquisados pelo projeto: a) as motivações que levaram os estudantes a estudar fora do país; b) as dificuldades e desafios encontrados pelos estudantes. 0 contexto pesquisado foram três Instituições localizadas no sul do Brasil, duas no estado de Santa Catarina e uma no Rio Grande do Sul. Participaram da pesquisa 210 intercambistas, sendo 103 estudantes brasileiros que fizeram intercâmbio em Instituições estrangeiras e 107 estudantes africanos que estudaram em IES do sul do Brasil. O texto está trabalhado em unidades de análise, sendo as motivações a primeira unidade de análise, dividida em duas categorias: a) aproximação da linguagem materna e a imersão cultural; b) formação acadêmica. Quanto às dificuldades, foram observadas também duas categorias: a) o sentimento de distanciamento e b) a discriminação social. Em relação aos desafios identificou-se questões voltadas para os processos de ensinar e aprender nas IES.

Palavras-chave: Educação superior. Internacionalização. Mobilidade estudantil.

\section{Abstract}

This research has the internationalization as investigating theme and intend to understand how the mobility experience is seen by the student. As the mobility is one of the main aspects in which the Brazilian university had in recent years a major role, the text analyzes the Brazilian students' opinions about the experience of studying in other countries and the African students' opinion who studied in higher education institutions in southern Brazil. We chose to present in this text only two foci among several surveyed by the project: a) the motivations that led students to study abroad; b) the difficulties and challenges encountered by students. The researched context were three Higher education Institutions located in southern Brazil, two in the state of Santa Catarina and one in Rio Grande do Sul. The research participants were 205 exchange students, including 103 Brazilian students, who did exchange in foreign institutions and 102 African students. Regarding to the first analysis unit- the motivations-, there are two categories: a) approach the mother language and cultural immersion; and b) academic training. The difficulties also stand out two categories: a) the sense of detachment and b) social discrimination. Regarding the challenges, the project identifies issues facing the processes of teaching and learning in HEls.

Keywords: College education. Internationalization. Student mobility.

Recebido em: 25/08/2016 - Aprovado em: 14/11/2016

http://dx.doi.org/10.5335/rep.v24i1.6990

Professora do Programa de Pós-Graduação em Educação da Unicamp. Doutora em Educação pela Unicamp. E-mail: eaguiar@unicamp.br

* Professora do Programa de Pós-Graduação em Educação da Universidade Regional de Blumenau - Furb. Doutora em Educação pela Unicamp. E-mail: selpamarcia@gmail.com

*** Professora do Mestrado Interdisciplinar Desenvolvimento e Sociedade e do Mestrado Profissional em Educação da Universidade Alto Vale do Rio do Peixe - UNIARP. Doutora em Educação pela Unisinos. E-mail: marialvamoog@hotmail.com 


\section{Introdução}

A sociedade contemporânea global, estruturada sob regras das grandes empresas transnacionais, sustenta-se da instrumentalidade do conhecimento e das competências técnicas internacionais. Nesse panorama, as universidades vêm, consciente ou inconscientemente, desempenhando papel de relevo, uma vez que prepara profissionais habilitados e capacitados para trabalhar nas questões técnicas, políticas, financeiras, sociais e culturais que estruturam a globalização.

O processo de internacionalização na educação superior vem crescendo desde os anos 1980 e, neste século XXI, tem crescido, expressivamente, em diferentes aspectos como: a mobilidade de docentes e discentes; a extensão de campus em diferentes países; a interculturalidade no currículo, bem como o desenvolvimento de parte dele em outros países; desenvolvimento conjunto de projetos de pesquisas, organização de eventos sobre determinada temática.

Pereira e Passos (2015, p. 51) ressaltam que a internacionalização do Ensino Superior "não é uma característica nova, como pode parecer. O início da universidade é marcado pela mobilidade dos estudantes europeus para estudar nas poucas universidades existentes na Idade Média" e reforçam que desde as duas últimas décadas do séc. XX, os programas de mobilidade educacional cresceram significativamente, cada qual com seu propósito, mas todos

[...] com laços transnacionais, estabelecendo conexões e criando redes de saber que pretendem, novamente, atingir a dimensão da troca universal por meio da inter-relação de estudantes, docentes, gestores e comunidades científicas, reforçando a premissa de que a universidade é ainda a instituição que pode promover a integração dos conhecimentos, da cultura, dos valores dos povos e o respeito pelas diferenças e especificidades de cada nação (PEREIRA; PASSOS, 2015, p. 51).

Assim, entre as muitas interfaces com a globalização, se fortalece a política de internacionalização no contexto universitário brasileiro. Nesse cenário múltiplo, muitas universidades assumiram a internacionalização como uma de suas funções, ao lado do ensino, pesquisa e extensão, o que já ficou denominada de a quarta missão da universidade por Almeida e Santos (2012). Os autores apontam que a internacionalização se transforma em missão da universidade quando esta é capaz de a mobilizar de forma intencional e consciente.

Da mesma forma, Morosini (2006) reconhece que tem sido uma característica da universidade moderna o trabalho conjunto de pesquisadores de várias partes do mundo em desenvolvimento de projetos, uma vez que "a universidade sempre teve como norma a internacionalização da função pesquisa, apoiada na autonomia do pesquisador" (MOROSINI, 2006, p. 108). 
No entanto, podemos afirmar que tem havido uma intensificação quanto à internacionalização da Educação Superior, proporcionada por diferentes políticas como: o aumento de concessões de pesquisa internacional e projetos internacionais de pesquisa cooperativados; associações internacionais envolvendo consultorias para universidades estrangeiras; universidades privadas com campus internacionais; colaboração em conselhos; dupla diplomação; doutorado em cotutela e doutorado sanduíche. A internacionalização traz, agregada em si, a possibilidade de alcançar alguns dos valores universitários enfatizados atualmente como: a diversidade cultural; o plurilinguismo; a flexibilidade curricular; a integração de áreas; a investigação em redes temáticas; o compartilhamento de conhecimentos. Com isso, a universidade assume um protagonismo na positividade da globalização, por favorecer a formação de um estudante aberto ao multiculturalismo, à multiversidade, à multireferencialidade. Retoma-se desde o início deste século, e com mais força, a movimentação de acadêmicos (professores, alunos e pesquisadores) entre centros de saberes, favorecendo partilhas de experiências e conhecimentos.

No contexto de internacionalização, destacam-se ações conjuntas entre o governo e as universidades, proporcionando acordos estratégicos em relação a ofertas de programas oferecidos pelas agências internacionais, entre eles: as bolsas para a formação em pós-graduação no exterior e o apoio aos projetos de pesquisa, gerando possibilidades de intercâmbio (LAUS, 2004). Da mesma forma, desenvolve-se na União Europeia inúmeros programas e subprogramas de mobilidade, assim como projetos de internacionalização que impulsionam reformas e inovações no Ensino Superior (PEREIRA; PASSOS, 2015).

No Brasil, o processo de internacionalização teve uma significativa presença nos programas de pós-graduação no século XX e, desde o início de 2000, intensifica-se na graduação por meio de convênios diretos entre universidades brasileiras e estrangeiras e por meio de programas governamentais. Entretanto, a partir de 2011, a mobilidade acadêmica no ensino superior cresce com a criação do Programa Ciência sem Fronteiras (PCF), implementado pelos Ministérios da Ciência, Tecnologia e Inovação (MCTI) e Ministério da Educação (MEC), por meio de suas respectivas Instituições de Fomento, CNPq e Capes e pelas Secretarias de Ensino Superior e de Ensino Tecnológico do MEC.

O Programa Ciência sem Fronteiras, criado pelo Decreto no 7.642 , de 13 de dezembro de 2011, possibilitou que os estudantes de graduação pudessem realizar intercâmbio de até um ano, retornando, após esse período, à universidade de origem para completar os créditos acadêmicos do seu curso. De acordo com os dados da Capes e CNPq, registrado no Relatório de Avaliação de Políticas Públicas em 2015, entre os anos de 2011 e 2014 foram concedidas e aceitas pela Instituição no exterior 101.446 bolsas, destas, 78.980 foram destinadas para a graduação sandu- 
íche. Portanto, há um número expressivo de estudantes de graduação que tiveram a oportunidade de estudar em diferentes universidades estrangeiras.

Sob outro ponto de vista, o Brasil tem sido uma possibilidade interessante para estudantes estrangeiros provenientes dos Palop - Países Africanos de Língua Oficial Portuguesa - que buscam formação inicial em IES brasileiras. Os estudantes consideram que o país tem forte influência dos costumes africanos, uma reconhecida qualidade de ensino e possui a mesma língua falada.

A mobilidade acadêmica de estudantes para graduação e pós-graduação em universidades estrangeiras tem se intensificado, consideravelmente, nas últimas décadas, tanto de brasileiros para o exterior, quanto de estrangeiros para nosso país, especialmente para universidades de ponta como USP e Unicamp, consideradas primeira e segunda melhores universidades da América Latina pelo Ranking Quacquerelli (QS/2016). No mesmo ranking, outras seis universidades brasileiras figuram entre as vinte melhores da América Latina ${ }^{1}$, qualidade que atrai estudantes de vários países latino-americanos a estudarem no Brasil.

Segundo Knight (2004) os motivos que levam os estudantes a interessar-se pela mobilidade e internacionalização estão classificados em cinco grupos: motivos políticos; motivos econômicos; sustentabilidade financeira; motivações socioculturais; motivos acadêmicos; motivos mercadológicos, de marketing e venda das atividades acadêmicas como produtos.

Altbach e Knight (2007, p. 5) apresentam ainda as motivações de caráter individual e pessoal como também significativas e apontam que estudantes, mesmo sem auxílio financeiro institucional ou outro tipo de apoio, decidem buscar desenvolver-se academicamente para estudar por conta própria em outro país. Para eles, "os estudantes acabam compondo a maior fonte de recursos financeiros para a internacionalização".

Por se ter tido, ultimamente, uma intensificação na mobilidade de acadêmicos, quer de estudantes, quer de docentes, pesquisadores e administradores, o tema da internacionalização vem sendo objeto de um número maior de estudos, de pesquisas e trabalho de sistematização. Amal e Borges (2015, p. 76) pesquisaram sobre o tema e apontam que o intercâmbio de estudos é a modalidade mais ativa no fenômeno da internacionalização. Em suas palavras: "percebe-se que o intercâmbio de alunos é o modo mais citado de acordo com as pesquisas realizadas, seguido pelo intercâmbio de professores e adaptação de currículos".

Embora o intercâmbio seja apenas uma das formas de internacionalização de uma IES, percebe-se a necessidade de aprofundar estudos no campo da mobilidade estudantil, a partir das experiências dos estudantes brasileiros que retornam para suas Instituições de origem, bem como analisar as percepções dos estudantes afri- 
canos sobre sua formação em Instituições brasileiras. É ao desafio de analisar as experiências dos estudantes intercambistas africanos e brasileiros ao estudarem em outro país que esta pesquisa se propôs.

\section{0 contexto da pesquisa}

$\mathrm{Na}$ elaboração da pesquisa, verificou-se que os intercâmbios estão estruturados de várias formas. Considerando o contexto da mobilidade dos jovens acadêmicos brasileiros para as universidades estrangeiras e os dos jovens acadêmicos africanos que chegam às IES brasileiras, constata-se que a mobilidade se configura por meio de convênios entre universidades, programas governamentais de incentivo à internacionalização e há, ainda, formas independentes dos estudantes desenvolverem o intercâmbio.

Como o objetivo da pesquisa foi o de conhecer as opiniões dos intercambistas sobre a experiência vivida, ela circunscreve-se em apenas um dos lados do processo de intercâmbio, deixando de considerar o lado da Instituição. A pesquisa foi desenvolvida em várias etapas como apresentado a seguir. A investigação é de natureza qualitativa, de cunho exploratório e, como instrumento de levantamento de dados, foi utilizado questionário com questões abertas e fechadas para os estudantes intercambistas de três Instituições de Ensino Superior do sul do Brasil: uma Instituição Pública e outra Instituição Comunitária do estado de Santa Catarina; uma Instituição comunitária de direito privado de grande porte no Rio Grande do Sul. Todas foram escolhidas por terem um considerável número de estudantes que preenchiam os critérios da pesquisa, isto é, alunos brasileiros com experiência em Instituição no exterior e alunos africanos frequentando cursos nas Instituições.

$\mathrm{Na}$ fase inicial, a pesquisa coletou dados quantitativos obtidos pelo setor de Coordenadoria de Relações Internacionais - CRI de cada instituição. Nesse levantamento, foi possível identificar na Instituição Pública de Santa Cataria o número de estudantes brasileiros que entre os anos de 2011 a 2015 estudaram em IES estrangeiras. Reconhece-se que nesse período houve maiores possibilidades de ofertas de bolsas por meio dos convênios que a universidade possuía, e, em especial, a partir do Programa Ciência sem Fronteiras- PCsF.

Os estudantes africanos que ingressaram na Instituição Comunitária de Santa Catarina e na Instituição comunitária de direito privado do Rio Grande do Sul estão matriculados desde 2009, pois realizam cursos completos de graduação nas Instituições investigadas.

Após o mapeamento dos sujeitos, na segunda fase da pesquisa foram encaminhados os questionários. Em uma das Instituições, o formulário foi enviado por 
meio eletrônico, google docs e, nas outras duas instituições, os questionários foram aplicados diretamente em sala de aula.

Na instituição pública de Santa Catarina, contou-se com um universo de 282 acadêmicos, sendo que, desses, 103 responderam ao questionário no ano de 2015, formando uma amostra de 36,5\%. Já entre os estudantes africanos ingressantes nas duas Instituições, uma do estado de Santa Catarina e outra do Rio Grande do Sul, o universo foi de 250 , sendo que $107(42,8 \%)$ responderam ao questionário também no ano de 2015. A amostra se configurou com um total de 210 estudantes das três Instituições, ou seja, 38,5\% do total dos estudantes. Quanto ao país de origem desses estudantes, tem-se que 102 (cento e dois) são de Angola, 03 (três) da República Democrática do Congo e 02 (dois) de Cabo Verde. Para análise dos resultados obtidos, foi utilizada a metodologia da análise de conteúdo (BARDIN, 2010).

Dos objetivos da pesquisa, destacaram-se dois aspectos para a apresentação dos dados neste texto: a) as motivações que levaram os jovens a estudar fora do país; b) as dificuldades e desafios encontrados pelos estudantes.

\section{0 que dizem os estudantes sobre a experiência}

A partir do objetivo de analisar as experiências de estudantes brasileiros que estudaram em outros países e estudantes africanos que optaram por estudar em Instituições de Educação Superior no sul do Brasil, interessou-se por identificar as principais motivações que levaram tais estudantes a participar do intercâmbio, suas principais dificuldades e os desafios enfrentados no contexto universitário. Em relação às motivações, encontraram-se duas categorias: a) língua materna $\mathrm{e}$ a imersão cultural; b) formação acadêmica. Sobre as dificuldades e os principais desafios dos estudantes, destacou-se como uma das principais o sentimento de distanciamento e de discriminação social. Em relação aos desafios, identificaram-se questões voltadas para os processos de ensino e aprendizagem nas IES.

\section{Linguagem materna e a imersão cultural}

A maior parte dos acadêmicos brasileiros que vão para o exterior responderam que a principal motivação foi a de aprender e estudar um novo idioma, ou seja, o aperfeiçoamento de uma língua estrangeira, sobretudo a língua inglesa. No entanto, a pesquisa revela que os três países de destino dos estudantes da Instituição investigada foram: Portugal com o envio de 27 (vinte e sete) acadêmicos; Suécia 25 (vinte e cinco) e Alemanha com 22 (vinte e dois) alunos. Nota-se que Portugal é o país favorito dos intercambistas o que evidencia que a escolha foi pela aproximação 
da língua materna e não para aprender outra língua. Pesquisas no âmbito nacional revelam que o país mais procurado pelos estudantes brasileiros também é Portugal e talvez a preferência se deva ao fato de não haver problemas com a comunicação linguística. Esse pode não ser o país de preferência, mas a opção mais adequada, uma vez que para realizar intercâmbios em países de língua inglesa os estudantes têm que realizar os testes TOEFL e IELTS, ${ }^{2}$ que, para muitos, é um desafio, tanto pela ausência do inglês na sua formação, como pelo tempo que antecede o intercâmbio e impossibilita a preparação adequada para a realização dos testes.

Na questão da escolha pela Suécia, percebe-se que há um incentivo da própria universidade de origem, na qual há um convênio com várias universidades desse país, que são especialmente voltadas para cursos tecnológicos. E a opção pela Alemanha justifica-se pelo fato de parte dos estudantes ter aproximação com a língua, uma vez que a região da universidade de origem dos acadêmicos é de imigração europeia com colonização alemã.

O que chama a atenção nos estudantes angolanos e moçambicanos que vêm estudar no Brasil, é que, embora sejam de países de língua portuguesa, esta não é uma motivação mencionada de forma recorrente. Ao contrário, eles reportam que a linguagem e a escrita, muitas vezes, se constituem em um desafio a ser enfrentado. Um dos interlocutores diz: "o principal desafio que tenho enfrentado é a comunicação. Apesar de falarmos a mesma língua, alguns termos que são empregados aqui são desconhecidos para muitos de nós" (Estudante angolano).

Sabemos que países que falam a mesma língua, como no caso o Brasil e Angola, há diferenças na comunicação, o que demanda certas adaptações. Os atos linguísticos e demais elementos da cultura de cada povo diferem e isso define a identidade nacional. O desafio se dá por ser por meio da linguagem que as relações de significação são entendidas e dão sentido à realidade. Assim, foi possível detectar nos depoimentos, algumas dessas diferenças.

Os acadêmicos brasileiros e africanos em geral apontam a imersão cultural, equivalente a "conhecer e ter contato com as novas culturas" (Estudante brasileiro) no sentido da interculturalidade, como um fator essencial e determinante no processo de intercâmbio. "Era comum perceber alunos e professores de diversas partes do mundo. Na nossa sala eram mais de trinta diferentes nacionalidades" (Estudante brasileiro). A interculturalidade no contexto acadêmico, portanto, abrange campos sociais, geográficos, culturais. Assim conhecer novas culturas e novas pessoas também impulsionou os jovens a buscarem uma formação no exterior. "A vontade de estudar e viver fora por um tempo, conhecer outro país, outro povo, hábitos e costumes, o dia a dia, a gastronomia, tudo aquilo que forma um país" (Estudante angolano). 
Nos depoimentos pudemos verificar o valor dado à interculturalidade, o que tem sido apontado por Azevedo (2015, p. 29) como um dos aspectos mais importantes da internacionalização. Para ele, a internacionalização da educação superior, "se fundamenta substantivamente na interculturalidade". O autor entende que a interculturalidade, "é capaz de preservar as manifestações culturais dos diversos povos e grupos e, ao mesmo tempo, de promover a integração (não o integrismo), a liberdade, a fraternidade, a justiça social e a igualdade substantiva".

Os estudantes africanos, embora tenham escolhido o Brasil, relataram que, inicialmente, tinham preferência por países do hemisfério norte, mas como a oportunidade de bolsa era para o Brasil, aceitaram e sentem-se felizes por terem sido contemplados. Disseram ainda que alguns colegas que, mesmo depois de aceitarem, quando vieram, fizeram a troca de país na primeira possibilidade. Alguns foram transferidos para uma oportunidade surgida no Chile. Justificaram a situação como sendo o medo, deles e das famílias, em relação à violência no Brasil.

\section{A formação acadêmica}

Os acadêmicos brasileiros também registraram como aspectos motivadores a possibilidade de dupla diplomação e, ao mesmo tempo, complementam destacando "a importância de adquirir conhecimentos acadêmicos em outro país, bem como um diferencial em seu currículo profissional". Acreditam que, "com o intercâmbio as oportunidades profissionais crescem, mas acima de tudo, o crescimento pessoal é o que faz a diferença" (Estudantes brasileiros).

A valorização do diploma estrangeiro também foi apontada pelos estudantes africanos como uma das motivações e a maioria deles alia esse aspecto a uma melhor colocação no mercado de trabalho, isto é, relacionam o diploma à possibilidade de melhoria no emprego. "O diploma de um país estrangeiro tem mais peso e aí consigo encontrar um emprego com maior facilidade" (Estudante angolano). Esse depoimento nos remete aos estudos de Peña (2014) quando afirma que os jovens estão cada vez mais conscientes sobre as vantagens de uma formação internacional para ter melhor acesso ao mundo do trabalho.

Um dos estudantes questiona a desvalorização das universidades africanas:

Não sei por que, mas nossas universidades não são reconhecidas e já tem muito tempo de história e já formou vários líderes africanos e de outros lugares que iam para lá, mas até agora não é reconhecida. Não sei se é o fraco orçamento que disponibilizam para a área da educação...então é isso que faz a maioria dos estudantes querer sair do país para estudar fora. 
Os estudantes africanos mencionaram também a qualidade de ensino e formação no Brasil, um deles afirmou que "o que me motivou estudar no Brasil foi a qualidade de ensino e a qualidade na formação profissional” (Estudante angolano). Apontaram ainda como motivo o fato de, no Brasil, haver maior opção de cursos de graduação e um deles diz "primeiro pelos variados cursos existentes, pela extensão da escolha e pelo que pode ser feito com o curso que escolhi" (Estudante angolano).

A influência familiar também foi apontada pelos estudantes africanos e brasileiros como decisiva para estudar em outro país, considerando a formação acadêmica de qualidade e o status do futuro reconhecimento no campo profissional, via de regra, pela busca do "sucesso no mercado de trabalho" (Estudante angolano), "possibilidades de trabalho e reconhecimento do seu currículo" (Estudante brasileiro). A decisão e a motivação dos pais tornam-se ainda mais forte quando é vislumbrada uma oportunidade de bolsa de estudos.

Em relação às áreas do conhecimento e respectivos cursos em que os acadêmicos brasileiros frequentaram no exterior, os dados mostram a prevalência de alguns campos do saber como: Ciências Exatas (35\%); Ciências Sociais Aplicadas (26\%); Cursos Tecnológicos (26\%); Ciências Humanas (5\%); e Ciências da Saúde (5\%).

Já os estudantes africanos que vieram como bolsistas de empresas que os prepara para assumir postos de trabalho em Angola, por exemplo, a maioria cursa Engenharia Cartográfica, Geologia e cursos próprios para sua futura área de atuação.

\section{Dificuldades e desafios no contexto acadêmico}

Quanto às possíveis dificuldades de adaptação na Instituição de Ensino Superior Estrangeira, os estudantes brasileiros relatam, na sua maioria, que não houve dificuldades significativas representando um índice de $45 \%$ acadêmicos. Entretanto, $40 \%$ dos intercambistas responderam que em alguns momentos sentiram dificuldades e 15\% assinalaram que tiveram dificuldades no que tange à adaptação ao país durante o Intercâmbio, em especial nos primeiros meses. As maiores dificuldades foram em relação à língua e aos costumes do país. "Confesso que as primeiras experiências com a língua foram frustrantes e engraçadas, percebi logo cedo que no cotidiano é muito diferente do que se aprende em um curso de idiomas" (Estudante brasileiro). Destacam que com o passar do tempo, os estranhamentos e as dificuldades tornam-se menos evidentes e a superação ganha espaço, "quando você passa a morar em um outro país e a falar a linguagem deles diariamente, você aprende o idioma de fato", (Estudante brasileiro). Outro estudante aponta que as relações de aproximação com os colegas não foram acolhedoras, "no começo não foi nada fácil. 
Os estudantes da universidade eram pessoas fechadas, não se aproximavam, ainda mais quando se tratava de aluno brasileiro em mobilidade" (Estudante brasileiro).

Os estudantes africanos relataram algumas dificuldades mais voltadas à sua aceitação e ao acolhimento do Brasil a eles que deixou a desejar por não se sentirem bem acolhidos pelos colegas da turma e relataram suas percepções e sentimentos: "Por parte dos colegas, houve certo grau de indiferença e sarcasmos" (Estudantes angolanos). Este fato demonstra a importância de se trabalhar o entendimento da diferença cultural e a atitude de aceitação cultural em nossas escolas e Instituições de Ensino Superior.

Isso ocorreu também com os estudantes brasileiros que foram para o exterior, "é possível sentir um certo distanciamento entre as pessoas que costumam ser mais reservadas" (Estudante brasileiro). Mesmo nos casos de países que falam a mesma língua existem "guetos culturais" em que o outro nem sempre é bem-vindo. Percebe-se que os estudantes locais nem sempre percebem o estrangeiro e não fazem questão de 0 acolher, por fatores que ainda não podemos responder neste estudo. Nesses casos, ocorre que tanto estudantes que saem do Brasil como os que chegam para aqui estudar acabam formando um grupo dos "outros", isto é, dos que não são os locais.

Os estudantes africanos relataram, também, dificuldades financeiras, principalmente por aqueles que não possuem nenhum tipo de subsídio para custear as despesas de mensalidades, alimentação, transporte e moradia. Um deles disse que "a verdadeira dificuldade é a questão financeira, a falta de subsídios que se traduz na falta de alguns pagamentos, como é o caso das propinas ${ }^{3}$ da universidade e do aluguel. De uma forma ou de outra acaba por afetar o rendimento do estudante".

Essa situação foi diferente entre os estudantes brasileiros pois, em grande parte, tinham bolsas de estudos que cobriam as despesas essenciais. Entre os que tinham bolsas do Programa Ciência sem Fronteiras, os valores eram expressivos e permitiam aos intercambistas conhecerem outros países durante o período de sua estadia.

Um outro desafio enfrentado pelos estudantes africanos foi o de superar a saudade familiar. O tempo de duração da graduação, de quatro a cinco anos, é tido como um tempo bastante significativo e esses afirmam que "estudar fora nos obrigar a crescer de uma hora para outra, porque já não tens mais a mãe para passar a mão nos nossos erros" (Estudante angolano).

Quanto aos estudantes brasileiros de graduação, o período de estadia em outro país gira em torno de seis meses até um ano e meio. Embora represente um período relativamente curto, os estudantes também manifestam o sentimento de saudades dos familiares, mas expressam suas aprendizagens, "uma hora ou outra a saudade 
aperta, mas tudo vale a pena. São tantas as descobertas que nos perdemos em meio às novidades", "embora tivesse saudades da família, desenvolvi mais a minha autonomia, aprendi a resolver meus problemas sozinho, a assumir as tarefas de casa, aprendi a conviver e a compreender as diferentes culturas que desconhecia" (Estudantes brasileiros).

Os estudantes africanos apontaram o racismo e a discriminação social como problemas que afetam as relações sociais. A discriminação aparece nos depoimentos e foi percebida por eles tanto de forma clara como de forma velada, sutil. "O maior desafio talvez seja o racismo silencioso das pessoas que talvez seja por ignorância" (Estudante angolano).

Um dos depoimentos no questionário mostrou o grau de discriminação sentida por pelos estudantes em sala de aula: "Em trabalhos em grupos sentia muito receio, pois parte dos colegas fugiam em trabalhar com angolanos porque acham que não sabemos nada" (Estudante angolano). Além disso, o sentimento que aflorou a partir dessa constatação ficou expressa nesta manifestação: "pensar em racismo é algo que doí lá dentro" (Estudante angolano).

Embora os problemas e desafios sejam muitos, ainda assim, os estudantes africanos continuam nas instituições e apresentam expectativas importantes quanto ao retorno ao país de origem.

\section{As relações professor e aluno nos processos de ensinar e aprender}

Os acadêmicos intercambistas brasileiros descrevem alguns desafios relacionados aos processos de ensinar, aprender e de adaptação ao currículo. Evidenciaram que a relação professor-aluno é bastante formal e os professores possuem um status diferenciado, com certa hierarquia. Um dos estudantes brasileiros menciona que "era visível o desprazer de um professor quando um aluno chegava atrasado à sua disciplina", ao contrário das universidades brasileiras, onde a relação professor aluno é mais informal e acessível. Por outro viés, os estudantes reconhecem a competência, a vasta experiência e o conhecimento científico dos professores. Os estudantes mencionam que os docentes possuem premiações internacionais e são valorizados pela comunidade em geral.

Outro ponto observado é que os docentes de algumas instituições estrangeiras estão, continuamente, disponíveis para os atendimentos extraclasses, em que oferecem orientações e tiram dúvidas dos alunos a respeito dos conteúdos apresentados, das avaliações e projetos a serem realizados. Entretanto, chama a atenção que, praticamente em todas as IES estrangeiras, os estudantes têm como perfil a independência do professor, o autodidatismo e autonomia nos estudos. 
Para os africanos, é ponto alto da educação brasileira a liberdade que o professor proporciona ao aluno para dialogar com ele durante suas explicações. Os estudantes africanos demonstraram certa dificuldade em relação à metodologia $\mathrm{e}$ conteúdos desenvolvidos no Brasil a que tiveram que se adaptar. O ensino no Brasil é visto por eles como sendo mais prático, enquanto que em Angola é mais teórico. Na perspectiva dos estudantes angolanos, os professores brasileiros "passam" os conteúdos mais detalhadamente, fato que consideram positivo. Em Angola o professor não sintetiza os conteúdos, o que leva o aluno a pesquisar e estudar mais.

\section{E após a formação no exterior, o que fazer?}

Sobre as perspectivas dos estudantes ao retornar ao país de origem, a partir da formação obtida no Brasil ou no exterior, perguntamos o que esperavam fazer. Foi possível perceber que são distintas as perspectivas de cada grupo.

Os estudantes brasileiros quando vão para uma experiência no exterior vislumbram uma oportunidade de ficar no país, principalmente quando se trata de um país desenvolvido. No caso do Programa Ciência sem Fronteira, os estudantes têm que voltar para finalizar a graduação e a expectativa de ficar no país não se confirma. Entretanto, expressam constantemente o desejo de voltar ao país visitante.

Os estudantes africanos têm um compromisso muito maior com o seu país, com sua reconstrução e desenvolvimento e visam à aplicação dos conhecimentos adquiridos na reconstrução do país. Um dos estudantes afirmou: "após a minha formação espero retornar para suprir com as necessidades e ajudar o meu país a se desenvolver" (Estudante angolano).

Um número significativo de estudantes se referiu ao crescimento e reconhecimento pessoal como a maior expectativa ao retornar ao país de origem.

\section{Considerações finais}

A pesquisa sobre mobilidade estudantil nos auxiliou a entender um dos fatores que é bastante comum entre os estudantes que se mobilizam para estudar fora, a saber: a busca por uma formação melhor, tanto acadêmica quanto cultural e a aquisição de conhecimento em países que julgam ser mais desenvolvidos do que o seu.

A língua, por ser uma referência fundamental, ocupa papel importante na escolha do país de intercâmbio. Ou o estudante procura o país com a mesma língua materna, ou aceita outra língua com o intuito de vencer o desafio de aprendê-la, pois julga que esse conhecimento será um diferencial para melhorar seu currículo. 
Todos os estudantes dizem querer tirar o máximo de aprendizagem do período do intercâmbio para uma melhora pessoal em termos culturais e em termos acadêmicos.

No entanto, a experiência de chegar em um lugar que não é o lugar de origem, provoca não só insegurança, como enormes desafios para a sociabilidade, pois muitas vezes a presença do "estrangeiro" também gera estranhamento nos nativos e leva a uma atitude de autoproteção do grupo local. É comum que, quem chega está aberto a conhecer o diferente, mas quem está no local, tende a se fechar, pois entende não precisar desses estrangeiros para se sentir bem em suas comunidades.

Nota-se que o incentivo das famílias brasileiras para os intercambistas é a ideia de buscar uma vida melhor fora do Brasil, o que é despertado pelas condições sociais, econômicas e de segurança atuais. Já os estudantes africanos são educados pela sua família e pela instituição de origem a voltar para o país, pois esse precisa deles e da experiência adquirida fora, para melhorar e se reconstruir. Isso ficou muito claro pelas respostas que deram à questão da motivação e das expectativas de estudar fora do país e pelo sentimento de compromisso que expressaram nelas.

Podemos afirmar que a mobilidade, sendo uma das formas da internacionalização, está sendo assumida pelas universidades como uma nova função ao lado das funções de ensino, pesquisa e extensão. A experiência do intercâmbio tem uma avaliação muito positiva como oportunidade acadêmica de interculturalidade, de desenvolvimento da autonomia pessoal, de ampliação cultural e de possíveis novas oportunidades no mundo do trabalho. Nesse processo de imersão cultural e acadêmica, um dos estudantes menciona que "certos traços de nossas personalidades mudaram com o intercâmbio, a visão de mundo não é a mesma".

No geral, todos os alunos avaliaram como de grande significado o tempo passado em universidades estrangeiras, mas podemos entender que a boa avaliação sempre recai na experiência vivida em países considerados mais desenvolvidos que o de origem. Isso foi apresentado tanto pelos estudantes brasileiros como pelos dos países africanos. Pode-se concluir que a internacionalização é vista pelos intercambistas de países em desenvolvimento ou subdesenvolvidos como uma oportunidade do diferencial necessário para uma melhor colocação no mundo do trabalho, o que se estende, igualmente, a intercambistas brasileiros e africanos. No entanto, nenhum dos estudantes brasileiros apontou a importância de adquirir conhecimentos que pudessem beneficiar o desenvolvimento do país, sendo esse um dos propósitos dos programas de internacionalização. Entretanto, para os africanos, o conhecimento adquirido é visto, primeiramente, como necessário para auxiliar no desenvolvimento do seu país e é desse modo que entendem o diferencial na sua formação pessoal e profisssional. 


\section{Notas}

1 As seis melhores universidades brasileiras entre as vinte melhores da América Latina, segundo o Quacquerelli Symonds (QS) de 2016 são: Universidade Federal do Rio de Janeiro (UFRJ), Universidade de Brasília (UnB), Universidade Estadual Paulista (Unesp), Universidade Católica do Rio de Janeiro (UCRJ) e Universidade Federal do Rio Grande do Sul (Ufrgs).

2 TOEFL - Test of English as a Foreign Language, é o exame Norte Americano mais conhecido; e IELTSInternational English Language Testing System, é o exame Britânico mais conhecido. Ambos têm como objetivo principal avaliar o domínio da Língua de quem quer ingressar em suas universidades.

3 Em Angola, o valor a ser pago pelo curso que é dividido em parcelas mensais, cada parcela ou prestação, é chamada de propina.

\section{Referências}

ALMEIDA, Naomar; SANTOS, Fernando Seabra. Internacionalização universitária na sociedade do conhecimento. [S.l.]: Universidade de Coimbra; Universidade de Brasília, 2012.

ALTBACH, Philip G.; KNIGHT, Jane. The internationalizacion of higher education: motivations and realities. Journal of Studies in Internacional Education, 11, v. 3, n. 4, p. 290-305, 2007.

AMAL, Mohamed; BORGES, Gustavo da Rosa. Internacionalização de Instituições de Ensino Superior: uma perspectiva sobre a mobilidade estudantil. In: PEREIRA, Elisabete Monteiro de Aguiar; HEINZLE, Marcia Regina Selpa (Org.). Internacionalização na Educação Superior: políticas, integração e mobilidade acadêmica. Blumenau: Editora Furb, 2015.

AZEVEDO, Mário Luiz Neves de Azevedo. Internacionalização e transnacionalização da Educação Superior: trata-se de formação de um campo social global ou de um mercado mundial em construção? In: PEREIRA, Elisabete Monteiro de Aguiar; HEINZLE, Marcia Regina Selpa (Org.). Internacionalização na Educação Superior: políticas, integração e mobilidade acadêmica. Blumenau: Editora Furb, 2015.

BARDIN, Laurence. Análise de conteúdo. 4. ed. rev. e atual. Lisboa: Edições 70, 2010.

BRASIL. Decreto no 7.642, de 13 de dezembro de 2011. Institui o Programa Ciência sem Fronteiras. Diário Oficial da União [da] República Federativa do Brasil, Presidência da República, Brasília, DF, 14 dez. 2011. Seção 1, p. 7.

. Ministério da Educação. Coordenação de Aperfeiçoamento de Pessoal de nível Superior. Relatório de gestão do exercício de 2014. Brasília, 2015. Disponível em: <http://www.capes.gov.br/ images/stories/download/Contas_Publicas/2014_Relatorio_de_Gestao_CAPES.pdf>. Acesso em: 15 ago. 2016.

KNIGHT, Jane. Internacionalização remodeled: definition, approaches, and rationales. Journal of Studies in Internacional Education. Sage Publications, v. 8, n. 1, p. 5-32, Spring 2004.

LAUS, Sonia Pereira. Alguns desafios postos pelo Processo de Internacionalização da Educação Superior no Brasil. In: Gestão Universitária na América do Sul - IV Colóquio Internacional. Florianópolis: [s.n.], 2004.

MOROSINI, Marília Costa. Estado do conhecimento sobre internacionalização da Educação superior - conceitos e práticas. Educar, Curitiba: Editora UFPR, n. 28, p. 107-127, 2006. 
PEÑA, Daniel. Internacionalização. Que metas? A que ritmo? Que as estratégias? Universidade Carlos III de Madri, Espanha. In: ENCONTRO UNIVERSIA DE REITORES, 3, 2014. Rio de Janeiro, 2014.

PEREIRA, Elisabete Monteiro de Aguiar; PASSOS, Rogério Duarte Fernandes dos. In: PEREIRA, Elisabete Monteiro de Aguiar; HEINZLE, Marcia Regina Selpa (Org.). Internacionalização na Educação Superior: políticas, integração e mobilidade acadêmica. Blumenau: Editora Furb, 2015.

QUACQUERELLI SYMONDS (QS). University Ranking Latin America 2016. Disponível em: <www://topuniversities.com/latin-america-rankings>. Acesso em: 22 jul. 2016. 